\title{
KARAKTERISTIK SIFAT MEKANIK, KETAHANAN API DAN \\ PEMBAKARAN, DAN MORFOLOGI NANOKOMPOSIT CAMPURAN PVC DAN LDPE
}

\section{CHARACTERIZATION OF MECHANICAL, RESISTANCE TO FIRE AND BURNING, AND MORPHOLOGICAL PROPERTIES OF BLEND PVC AND LDPE NANOCOMPOSITE}

\author{
Arum Yuniari \\ Balai Besar Kulit, Karet, dan Plastik, Yogyakarta \\ E-mail: arumyuniari@yahoo.com
}

Diterima: 24 Februari 2014 Direvisi: 1 April 2014 Disetujui: 10 April 2014

\begin{abstract}
The purpose of the study was to determine the effect of addition of low density polyethylene (LDPE) and flame retardant on mechanical properties, resistant to fire and burning and morphology from the mixture of polyvinyl chloride (PVC), LDPE, flame retardant, and nanoprecipitated calcium carbonate (NPCC) as filler. The materials were mixed in laboplastomill at $215{ }^{\circ} \mathrm{C}$, torque speed 50 rpm, for 10 minutes. Nanocomposite was prepared by PVC/LDPE variations of 100/15; 100/20; 100/25; and 100/30 phr and flame retardant variations of 30 and 35 phr. The results showed that the hihger of LDPE in nanocomposite increased the hardness and impact resistance, however, it decreased the tensile strength, elongation at break, and density. Addition of flame retardant to the nanocomposites showed good resistance to fire and burning, and optimum mechanical properties were found in using of $35 \mathrm{phr}$ flame retardant. The morphology of the nanocomposite, were observed by Scanning Electron Microscope (SEM) confirmed that homogeneous mixture of LDPE dispersed in the PVC matrix.
\end{abstract}

Keywords: nanocomposite, PVC/LDPE blend, flame retardant, nanoprecipitated calcium carbonate (NPCC)

\begin{abstract}
ABSTRAK
Tujuan penelitian adalah untuk mengetahui pengaruh penambahan low density polyethylene (LDPE) dan flame retardant terhadap sifat mekanik, ketahanan terhadap api dan pembakaran serta morfologi nanokomposit campuran polyvinyl chloride (PVC) dan LDPE. Nanokomposit dibuat dari campuran PVC, LDPE, flame retardant dan nanoprecipitated calcium carbonate (NPCC) sebagai filler. Bahan-bahan dicampur menggunakan laboplastomill pada suhu $215{ }^{\circ} \mathrm{C}$, kecepatan torsi 50 rpm selama 10 menit. Nanokomposit PVC/LDPE dibuat dengan variasi 100/15; 100/20; 100/25 dan 100/30 phr serta variasi flame retardant (FR) 30 dan 35 phr. Hasil uji menunjukkan bahwa jumlah LDPE naik dalam nanokomposit: kekerasan dan ketahanan pukul takik menunjukkan kenaikan, tetapi kuat tarik, kemuluran, dan berat jenis turun. Penambahan flame retardant menyebabkan nanokomposit mempunyai ketahanan yang baik terhadap api dan pembakaran, dan optimun sifat mekanik diperoleh pada penggunaan flame retardant $35 \mathrm{phr}$. Morfologi nanokomposit campuran PVC dan LDPE diamati dengan Scanning Electron Microscope (SEM), campuran homogen LDPE terdispersi pada matriks PVC.
\end{abstract}

Kata kunci: nanokomposit, campuran PVC/LDPE, flame retardant, nanoprecipitated calcium carbonate (NPCC) 


\section{PENDAHULUAN}

Polivinil klorida yang dikenal dengan PVC merupakan polimer yang banyak digunakan untuk bahan baku produk elektronik, bahan konstruksi, kabel dan lain-lain. PVC bila dibandingkan dengan poletilen (PE) maupun polistiren (PS) sifat termal dan kemudahan diproses sangat rendah. PVC merupakan polimer dengan stabilitas termal rendah sehingga mudah terdegradasi. Salah satu upaya memperbaiki sifat termalnya adalah dengan cara dehidroklorinasi. Temperatur PVC pada saat proses dehidroklorinasi adalah sekitar $100^{\circ} \mathrm{C}$, pada kondisi tersebut terjadi pembentukan ikatan rangkap terkonjugasi dan polyene sequences (Saeedi et al., 2011). Pencampuran PVC dengan plasticizer berakibat pada penurunan sifat kuat tarik dan berat jenis tetapi meningkatkan kemuluran. Sedangkan penambahan bahan pengisi kedalam PVC dapat meningkatkan kuat tarik akan tetapi menurunkan kemuluran (Unar et al., 2010). Unar et al. (2010) dalam penelitiannya menyimpulkan bahwa penambahan aditif kedalam polimer PVC akan memberikan perubahan terhadap sifat fisika.

Low density polyethylene (LDPE) merupakan polietilena dengan kisaran densitas antara 0,910-0,925 g/ $\mathrm{cm}^{3}$ dengan cabang pendek maupun panjang. Perbedaan densitas akan mempengaruhi sifat-sifat polietilena antara lain sifat termal (titik leleh), sifat optik (haze, gloss, clarity), dan sifat fisika (ketahanan pukul takik, ketahanan sobek dan kuat tarik). Nanokomposit merupakan material baru yang saat ini dikembangkan. Penggunaan bahan pengisi berukuran nano dalam hal ini nanoprecipitated calcium carbonate (NPCC) diharapkan dapat tersebar dan terdispersi secara acak pada matriks polimer. Penyebaran partikel nano menghasilkan nanokomposit yang menunjukkan sifat superior (Yuniari dan Kasmudjiastuti, 2012). NPCC banyak digunakan dalam industri plastik terutama untuk produk high grade seperti automotive internal sealed dengan PVC plastisol. NPCC dapat meningkatkan reologi plastik. Komposit didefinisikan sebagai gabungan serat-serat dan resin. Penggabungannya sangat beragam, serat diatur memanjang (unidirectional composites), ada yang dipotong-potong kemudian dicampur secara acak (random fibers).

Komposit plastik yang dibuat dari campuran PVC dan LDPE sudah diteliti oleh Sombatsompop et al. (2004), yang menunjukkan bahwa penambahan LDPE kedalam PVC dapat mencegah serangan oksigen pada komposit. Kebaruan penelitian ini dibandingkan dengan penelitian sebelumnya adalah pada penambahan NPCC dan flame retardant. PVC sulit bercampur dengan LDPE sehingga agar dapat bercampur sempurna perlu tambahan compatibilizer (Khunsumled et al., 2007). Nanokomposit dari campuran LDPE dan nanoalumina menghasilkan sifat mekanik cukup baik (Chee et al., 2012). Deka et al. (2011) membuat nanokomposit dari campuran high density polyethylene, polipropilena, LDPE dan PVC dengan filler serbuk kayu dan nanoclay. Durmus et al. (2008) mempelajari sifat mekanik nanokomoposit (LLDPE)/clay. Kabdi et al. (2008) mempelajari campuran PVC dan LDPE dengan penambahan compatibilizer berupa chlorinated polyethylene (CPE). Flame retardant ditambahkan ke dalam kompon plastik agar komposit lebih tahan api. Jenis-jenis flame retardant antara lain: tetra bromo xylena, amonium bromida dan antimoni trioksida. Penelitian ini bertujuan untuk mengetahui pengaruh penambahan LDPE dan flame retardant terhadap sifat mekanik, ketahanan api dan pembakaran, dan morfologi nanokomposit campuran PVC dan LDPE.

\section{BAHAN DAN METODE \\ Bahan Penelitian}

Plastik yang digunakan pada penelitian ini adalah PVC granule ex Reiken Asahi Plastics Japan dan low density polyethylene (LDPE) merk Petiln dari Malaysia. Nano precipitated calcium carbonate (NPCC) yang digunakan merek Shengke produksi Shandong Haize Nanomaterials Co., Ltd., dengan spesifikasi NPCCA-601, $\mathrm{CaCO}_{3}$ (coated) $\geq 95 \%$, bentuk partikel kubus, ukuran partikel rata-rata: $40 \mathrm{~nm}$, moisture $\leq 0,5 \%$, brightness $\geq 90 \%$, absorpsi minyak: $25-40 \mathrm{ml} / 100 \mathrm{~g}$, specific gravity: 2,5 $\mathrm{g} / \mathrm{cm}^{3}$, specific surface area $(\mathrm{BET}) \geq 20 \mathrm{~m}^{2} / \mathrm{g}$, $\mathrm{HCl}$ insoluble: $0,1-0,2 \%$, derajat aktivitas: $\geq 99 \%$, pH: 8,5-10,5, surface coating agent: coupling agent. Bahan aditif yang digunakan adalah maleat anhidrat merk Justus sebagai compatibilizer, dicumyl peroksida sebagai inisiator, antioksidan (Master X-AOX), antimoni 
Tabel 1. Formulasi penelitian

\begin{tabular}{ccccc}
\hline Kode Sampel & PVC $(\mathrm{phr})$ & LDPE $(\mathrm{phr})$ & FR $(\mathrm{phr})$ & NPCC $(\mathrm{phr})$ \\
\hline P100/LD15/F30 & 100 & 15 & 30 & 10 \\
P100/LD20/F30 & 100 & 20 & 30 & 10 \\
P100/LD25/F30 & 100 & 25 & 30 & 10 \\
P100/LD30/F30 & 100 & 30 & 30 & 10 \\
P100/LD15/F35 & 100 & 15 & 35 & 10 \\
P100/LD20/F35 & 100 & 20 & 35 & 10 \\
P100/LD25/F35 & 100 & 25 & 35 & 10 \\
P100/LD30/F35 & 100 & 30 & 35 & 10 \\
\hline
\end{tabular}

trioksida sebagai flame retardant dari Jerman, kalsium stearat sebagai heat stabilizer buatan Singapura merk FACI, asam stearat dan DOP sebagai plasticizer.

\section{Peralatan Penelitian}

Peralatan untuk pembuatan nanokomposit terdiri atas: timbangan digital merk Mettler Toledo, Hot Blender, laboplastomil merk Toyoseiki, hydraulic press MN Vulcanizing Press Spec XLB, D 400 x 400 x 1, dan mesin pelletizing merk Suzhou. Alat uji meliputi: untuk uji morfologi: Scanning Electron Microscopy (SEM) merk JEOL JSM-6360LA, alat uji sifat mekanik: tensile strength tester merk Troning Albert tipe QC II-M-18, hardness tester merk Toyoseiki (Durometer D), Izod Impact Tester, dan Electro Densimeter merk Mirage EW200SG

\section{Metode Penelitian}

Nanokomposit PVC dan LDPE dibuat dengan formulasi seperti disajikan pada Tabel 1. Pencampuran semua komponen penyusun nanokomposit PVC/LDPE, dilakukan dengan laboplastomil merk Toyoseiki. Mesin laboplastomil dihidupkan sesudah mencapai suhu $215{ }^{\circ} \mathrm{C}$ semua bahan dimasukkan kedalam hopper, adapun torsi putaran adalah $50 \mathrm{rpm}$, sedangkan waktu komponding adalah 10 menit. Kompon yang diperoleh dimasukkan ke unit pelletizing untuk dibentuk menjadi pellet. Kompon untuk keperluan pengujian ditekan menggunakan hydraulic press pada suhu $215^{\circ} \mathrm{C}$ dalam waktu 10 menit.

Karakterisasi nanokomposit dilakukan terhadap parameter sebagai berikut: sifat mekanikal: densitas (ASTM D 792), kuat tarik dan kemuluran (ASTM D 638), berat jenis (ASTM D 792), kekerasan (ASTM D2240), pukul takik (ASTM D 256/56). Pengamatan mikostruktur nanokomposit campuran PVC dan LDPE dilakukan dengan Scanning Electron Microscopy (SEM). Pengujian dilakukan sebanyak 3 kali ulangan dan hasil yang disajikan merupakan rata-rata 3 kali ulangan.

\section{HASIL DAN PEMBAHASAN}

\section{Kuat Tarik Nanokomposit PVC dan LDPE}

Kuat tarik nanokomposit sangat dipengaruhi sifat dasar dari polimer itu sendiri. Pengaruh penambahan LDPE terhadap kuat tarik nanokomposit disajikan pada Gambar 1. LDPE mempunyai sifat kuat tarik lebih rendah dibanding PVC karena PVC lebih kaku. Dengan demikian apabila kedua polimer tersebut dicampur akan menghasilkan komposit dengan sifat mekanik campuran keduanya. Hasil uji

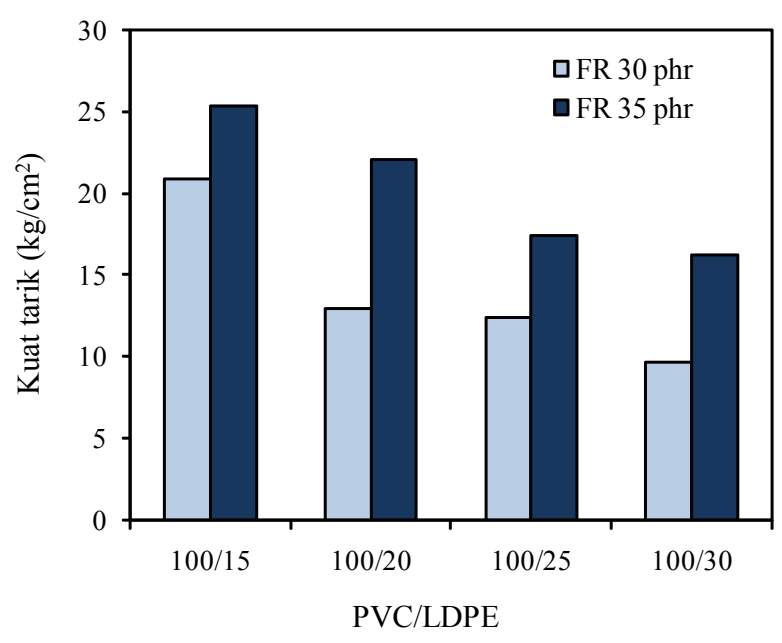

Gambar 1. Pengaruh jumlah LDPE terhadap sifat kuat tarik nanokomposit PVC dan LDPE 
menunjukkan setiap penambahan 5 phr LDPE kuat tarik cenderung turun. Nilai kuat tarik nanokomposit untuk semua formulasi dan jumlah flame retardant berkisar antara $9,68 \mathrm{~kg} /$ $\mathrm{cm}^{2}-25,35 \mathrm{~kg} / \mathrm{cm}^{2}$.

Kuat tarik nanokomposit PVC/LDPE juga dipengaruhi oleh flame retardant. Nanokomposit dengan jumlah flame retardant $35 \mathrm{phr}$ memberikan kuat tarik lebih tinggi daripada nanokomposit dengan jumlah flame retardant 30 phr. Flame retardant terbukti berfungsi sebagai aditif yang membantu terjadinya proses eksfoliasi antara PVC, LDPE, dan NPCC. LDPE terdispersi secara merata dalam matriks PVC dan terjadi proses reaksi kimia fisika (Laoutid et al., 2009). Penggunaan coupling agent maleat anhidrat dalam penelitian ini membantu meningkatkan sifat kuat tarik. Prachayawarakan et al. (2008) menyatakan bahwa penambahan maleat anhidrat pada campuran menyebabkan terjadinya reaksi kimia dan fisika karena adanya rantai non polar dari maleat anhidrat, akibatnya sifat mekanik komposit menjadi baik.

\section{Kemuluran Nanokomposit PVC dan LDPE}

Kemuluran nanokomposit (Gambar 2) dipengaruhi oleh jumlah LDPE dalam matriks campuran polimer, semakin banyak jumlah LDPE yang ditambahkan maka kemulurannya semakin turun. Penambahan LDPE dalam jumlah berlebihan erat hubungannya dengan dispersi LDPE dalam matriks PVC. Jumlah LDPE semakin banyak, kemuluran turun, hal ini disebabkan banyak fase yang tidak berikatan

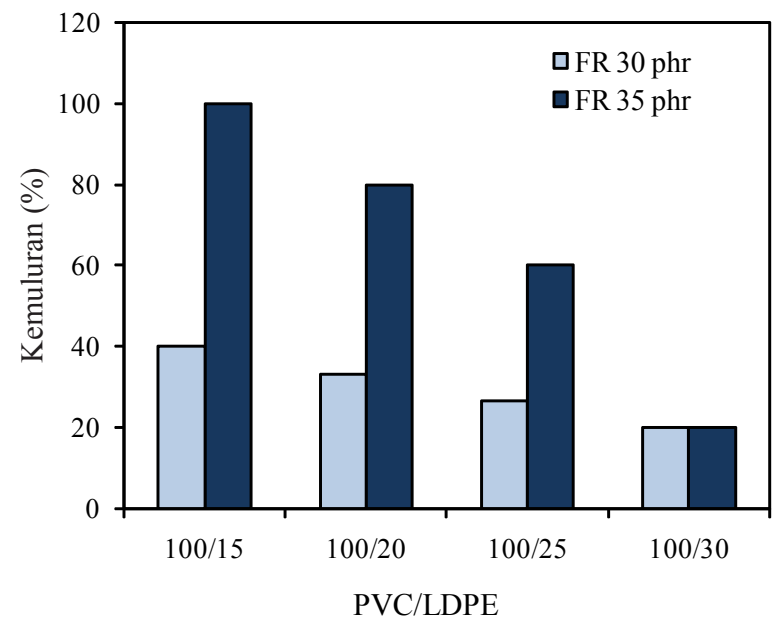

Gambar 2. Pengaruh jumlah LDPE terhadap kemuluran nanokomposit PVC dan LDPE satu sama lain (Thongpin et al., 2006). Selain itu Saeedi et al. (2010) menyatakan bahwa polyethylene dan PVC merupakan polimer dengan kekuatan adhesi rendah sehingga bila dicampur memberikan sifat mekanik kurang baik. Kemuluran nanokomposit berkisar antara 20,10-100\%. Kemuluran tertinggi dijumpai pada nanokomposit PVC/LDPE (100/15) dengan jumlah flame retardant $35 \mathrm{phr}$ yaitu sebesar $100 \%$. Sama halnya dengan kuat tarik nanokomposit $\mathrm{PVC} / \mathrm{LDE}$ untuk parameter kemuluran flame retardant juga berfungsi sebagai aditif yang berpengaruh pada proses reaksi kimia fisika. Hal ini mengakibatkan makin besar jumlah flame retardant kemuluran makin tinggi (Laoutid et al., 2009).

\section{Berat Jenis Nanokomposit PVC dan LDPE}

Berat jenis nanokomposit PVC disajikan pada Gambar 3. Berat jenis nanokomposit cenderung turun dengan bertambahnya jumlah LDPE. Hal ini disebabkan berat jenis PVC $\left(1,3-1,58 \mathrm{~g} / \mathrm{cm}^{3}\right)$ lebih besar dari berat jenis LDPE $(0,910-0,925$ $\left.\mathrm{g} / \mathrm{cm}^{3}\right)$.

Kenaikan LDPE 5 phr menurunkan densitas komposit sebesar 1,47\%. Penambahan LDPE ke dalam matriks PVC akan merubah struktur kristalinitas polimer, sebab LDPE merupakan polimer $100 \%$ kristalin, sedangkan PVC merupakan polimer semi kristalin (sydiotactic) (Samira et al., 2013). Penambahan jumlah flame retardant juga mempengaruhi berat jenis nanokomposit. Nanokomposit dengan flame retardant $35 \mathrm{phr}$ umumnya mempunyai berat jenis lebih

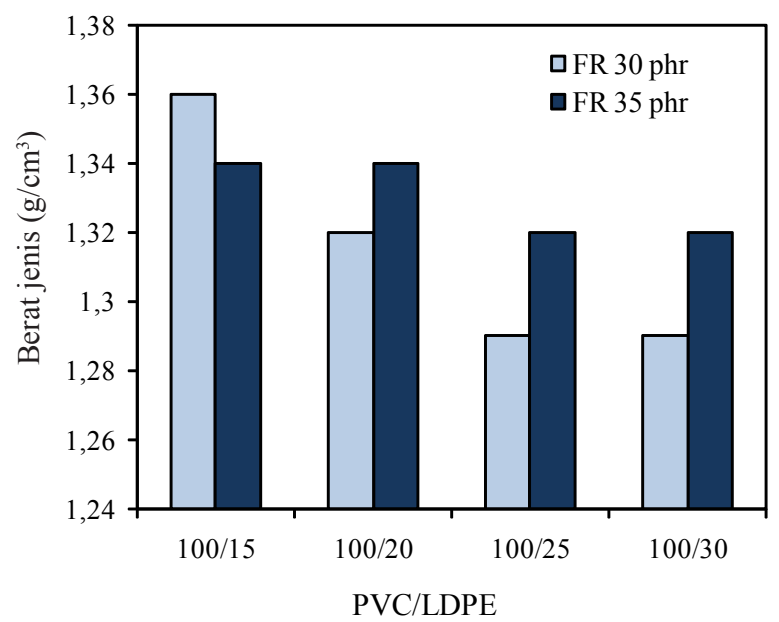

Gambar 3. Pengaruh jumlah LDPE terhadap berat jenis nanokomposit PVC dan LDPE 
tinggi dari pada nanokomposit dengan flame retardant $30 \mathrm{phr}$. Berat jenis nanokomposit mempunyai rentang $1,25-1,36 \mathrm{~g} / \mathrm{cm}^{3}$.

\section{Kekerasan nanokomposit PVC dan LDPE}

Kekerasan nanokomposit (Gambar 4) cenderung naik sejalan dengan bertambahnya jumlah LDPE. Hal ini dikarenakan LDPE merupakan polimer $100 \%$ kristalin dan PVC merupakan polimer semi kristalin (Chin, 2007).

Nilai kekerasan nanokomposit dengan variasi jumlah flame retardant $30 \mathrm{phr}$ dan 35 phr mempunyai rentang antara 88-90 shore A. Kekerasan tertinggi terjadi pada nanokomposit PVC/LDPE (100/30). Penambahan flame retardant sebagai additive terbukti memberikan pengaruh secara signifikan terhadap kekerasan. Jumlah flame retardant makin naik kekerasan nanokomposit naik demikian juga sebaliknya jumlah flame retardant turun kekerasan turun. Nanokomposit PVC/LDPE (100/30) dengan flame retardant 35 phr mempunyai kekerasan tertinggi yaitu 90 shore A.

\section{Ketahanan Pukul Takik Nanokomposit PVC dan LDPE}

Ketahanan pukul takik nanokomposit disajikan pada Gambar 5. Hasil uji menunjukkan makin banyak jumlah LDPE, nilai ketahanan pukul takik sangat berfluktuasi, artinya penambahan LDPE tidak secara signifikan mempengaruhi nilai ketahanan pukul takik.

Flame retardant berpengaruh terhadap nilai ketahanan pukul takik nanokomposit. Nano-

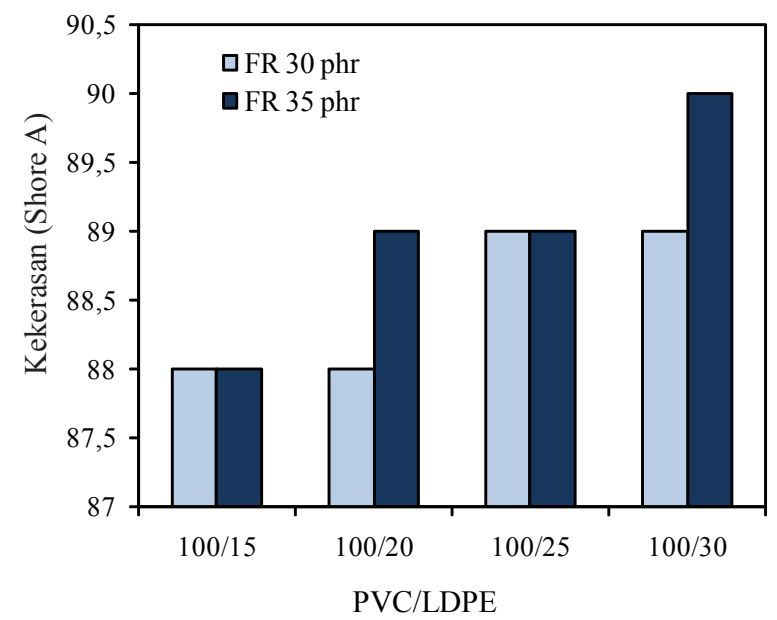

Gambar 4. Pengaruh jumlah LDPE terhadap kekerasan nanokomposit PVC dan LDPE komposit dengan jumlah flame retardant 35 phr memberikan nilai pukul takik lebih tinggi daripada nanokomposit dengan jumlah flame retardant $30 \mathrm{phr}$. Ketahanan pukul takik nano komposit dengan jumlah flame retardant $30 \mathrm{phr}$, PVC/LDPE (100/25) mempunyai nilai tertinggi yaitu sebesar $8,78 \mathrm{~kJ} / \mathrm{mm}^{2}$.

\section{Ketahanan Terhadap Api dan Pembakaran Nanokomposit PVC dan LDPE}

Hasil uji ketahanan terhadap api nanokomposit disajikan Tabel 2. Hasil uji ketahanan terhadap api dan pembakaran nanokomposit yang dilakukan pada suhu 650 ${ }^{\circ} \mathrm{C}$ terlihat bahwa semua nanokomposit dengan variasi LDPE maupun jumlah flame retardant sudah memenuhi persyaratan SNI 04-65042011: Lampu swa-balast untuk pelayanan pencahayaan umum - persyaratan keselamatan. Nanokomposit dibakar pada suhu $650{ }^{\circ} \mathrm{C}$ tidak menyala dan tidak ada tetesan.

Penambahan flame retardant pada nanokomposit PVC dan LDPE terbukti memberikan sifat ketahanan api dan pembakaran cukup baik (Chalid, 2011; Nurhajati et al., 2011; Chen et al., 2013).

\section{Analisis Mikrostruktur Nanokomposit PVC dan LDPE}

Mikrograf SEM dari campuran nanokomposit dengan variasi jumlah flame retardant (30 dan 35 phr) disajikan pada Gambar 6. Hasil uji dapat diamati bahwa fase minor LDPE

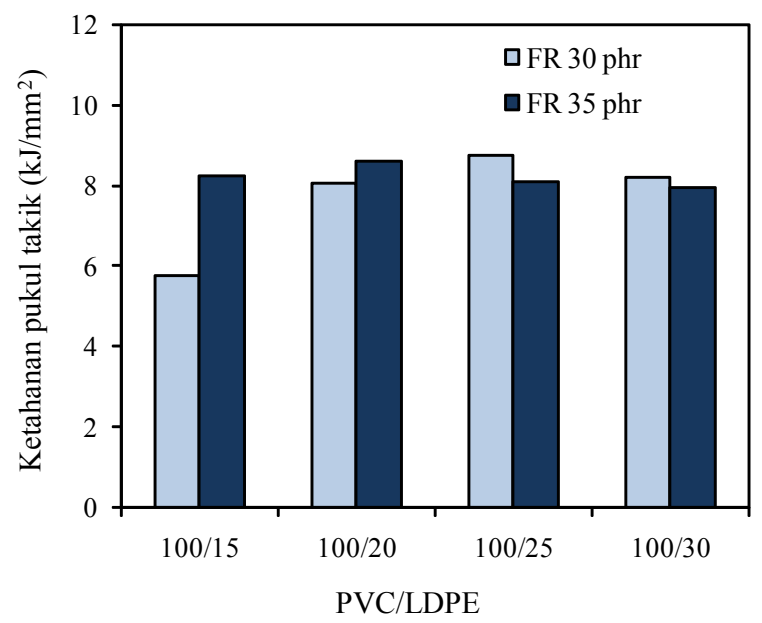

Gambar 5. Pengaruh jumlah LDPE terhadap ketahanan pukul takik nanokomposit PVC dan LDPE 
Tabel 2. Hasil uji ketahanan terhadap api dan pembakaran

\begin{tabular}{cc}
\hline PVC/LDPE/Flame retardant $(\mathrm{phr})$ & Ketahanan terhadap api dan pembakaran suhu $650{ }^{\circ} \mathrm{C}$ \\
\hline $100 / 15 / 30$ & Tidak menyala dan tidak ada tetesan \\
$100 / 20 / 30$ & Tidak menyala dan tidak ada tetesan \\
$100 / 25 / 30$ & Tidak menyala dan tidak ada tetesan \\
$100 / 30 / 30$ & Tidak menyala dan tidak ada tetesan \\
$100 / 15 / 35$ & Tidak menyala dan tidak ada tetesan \\
$100 / 20 / 35$ & Tidak menyala dan tidak ada tetesan \\
$100 / 25 / 35$ & Tidak menyala dan tidak ada tetesan \\
$100 / 30 / 35$ & Tidak menyala dan tidak ada tetesan \\
\hline
\end{tabular}

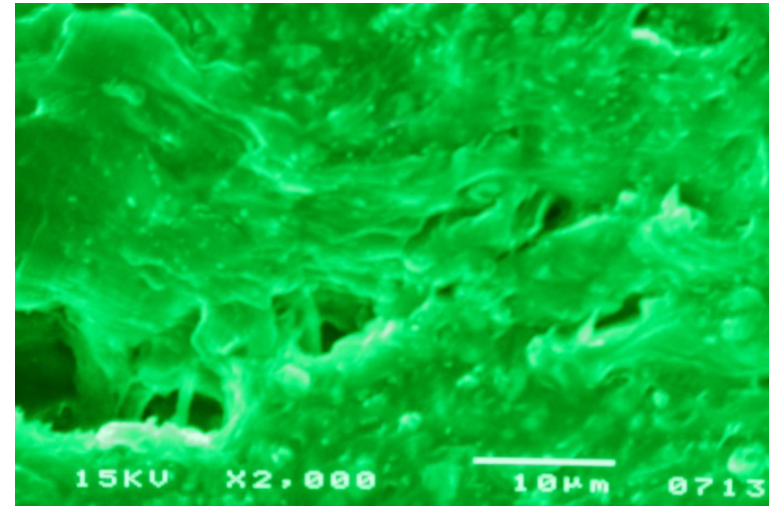

(a)

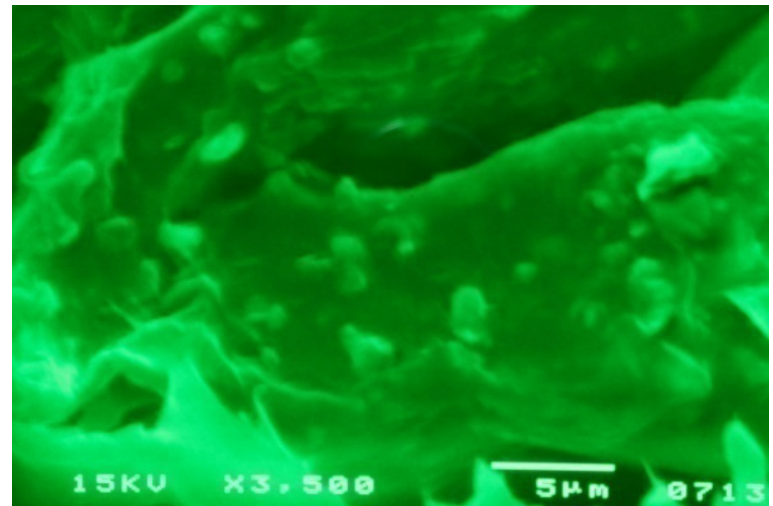

(b)

Gambar 6. Mikrograf SEM nanokomposit PVC untuk perbandingan komposisi PVC/LDPE (100/20): (a) flame retardant $30 \mathrm{phr}$ dengan perbesaran 2000x, (b) flame retardant $35 \mathrm{phr}$ dengan perbesaran 3500x.

tersebar pada matriks PVC, morfologi tidak terpengaruh keberadaan nano partikel NPCC. Partikel NPCC beraglomerasi sehingga ukuran partikel menjadi $10 \mu \mathrm{m}$. Kehadiran NPCC terletak di fase PVC tidak dalam domain LDPE. Compatibilizer maleat anhidrat mempengaruhi dispersi LDPE kedalam PVC sehingga campuran menjadi homogen. Penambahan flame retardant menyebabkan terjadinya reaksi fisiko kimia dan termo mekanis menyebabkan nano filler bersinergi dengan baik dan menghasilkan campuran yang kompatibel (Chen et al., 2013; Laoutid et al., 2009)

\section{KESIMPULAN}

Penambahan LDPE pada nanokomposit menyebabkan perubahan sifat mekanik, antara lain: penurunan kuat tarik, kemuluran, dan berat jenis. Sebaliknya penggunaan flame retardant dalam jumlah yang lebih tinggi (35 phr) menyebabkan peningkatan kuat tarik, kemuluran, berat jenis, kekerasan dan ketahanan pukul takik. Penambahan flame retardant menghasilkan nanokomposit tahan terhadap api dan pembakaran. Analisis morfologi nanokomposit dengan SEM menunjukkan campuran homogen LDPE terdispersi terhadap matriks polmer.

\section{UCAPAN TERIMA KASIH}

Penulis mengucapkan terima kasih kepada Ibu Ir. Niken Karsiati selaku Kepala Bidang Pengujian, Sertifikasi, dan Kalibrasi BBKKP yang telah membantu koordinasi pelaksanaan penelitian dan pengujian. Disamping itu ucapan terima kasih penulis sampaikan kepada Ibu Dra Sri Brataningsih PL atas bantuannya dalam hal pelaksanaan penelitian.

\section{DAFTAR PUSTAKA}

Chee, C. Y., Song, N. L., Abdullah, L. C., Choong, T. S., Ibrahim, A., and Chantara, T. R., 2012. Characterization of mechanical properties: low-density polyethylene nanocomposite using nanoalumina particle as filler, Journal of Nanomaterials, 2012. 
Chen, S., Sun, B., Huang, G., Guo, H., and Wang, S., 2013. Effects of an (Intumescent flame retardant) montmorillonite combination on the thermal stability and fire retardant properties of LDPE/EVA nanocomposites, Journal of Vinyl and Additive Technology, 19(4): 285-292.

Chin, S., 2007. Degradation behaviour of PVC$L D P E$ blend, Skripsi, Universiti Teknikal Malaysia Melaka.

Deka, B. K., Maji, T. K., and Mandal, M., 2011. Study on properties of nanocomposites based on HDPE, LDPE, PP, PVC, wood and clay, Polymer Bulletin, 67(9): 18751892.

Durmus, A., Kaşgöz, A., and Macosko, C. W., 2008. Mechanical properties of linear low density polyethylene (LLDPE)/clay nanocomposites: estimation of aspect ratio and interfacial strength by composite models, Journal of Macromolecular Science, Part B: Physics, 47(3): 608-619.

Kabdi, S. A. and Belhaneche-Bensemra, N., 2008. Compatibilization of regenerated low density polyethylene/poly(vinyl chloride) blends, Journal of Applied Polymer Science, 110(3): 1750-1755.

Khunsumled S., Prachayawarakorn J., Thongpin C., Kositchaiyong A. and Sombatsompop N., 2007. Property modification of composites between poly(vinyl chloride)/ low-density polyethylene polymer blends reinforced by hevea brasiliensis sawdust, Polymer Graduate Conference of Thailand, Mahidol University, Nakhonpathom.

Laoutid, F., Bonnaud, L., Alexandre, M., Lopez-Cuesta, J. M., and Dubois, P., 2009. New prospects in flame retardant polymer materials: From fundamentals to nanocomposites. Materials Science and Engineering: R: Reports, 63(3): 100-125.

Nurhajati, D. W., Yuniari, A. dan Kasmudjiastuti, E., 2011. Sifat elektrik dan termal nano komposit HDPE/NPCC, Majalah Kulit, Karet dan Plastik, 27(1):
Prachayawarakan, J., Khunsumfed, S., Thongpin, C., Kositchayong, A., and Sombatsompop, N., 2008. Effect of silane and MAPE coupling agent on the properties and interfacial adhesion of wood-filled PVC/ LDPE blend, Journal of Applied Polymer Science, 108: 3523-3530.

Saeedi, M., Ghasemi, I., and Karrabi, M., 2011. Thermal degradation of poly (vinyl chloride): Effect of nanoclay and low density polyethylene content, Iranian Polymer Journal, 20: 423-432.

Samira, M., Ahmed, M., Nadia N., Mohamed, S., and Rachida, Z., 2013. Thermal and mechanical properties of PVC and PVCHDPE blends, Research \& Reviews: Journal of Material Sciences, 1(1): 6-11.

Sombatsompop, N., Sungsanit, K. and Thongpin, C., 2004. Structural changes of PVC in PVC/LDPE melt-blends: Effects of LDPE content and number of extrusions, Polymer Engineering \& Science, 44(3): 487-495.

Thongpin, C., Santavitee, O. and Sombatsompop, N., 2006. Degradation mechanism and mechanical properties of PVC in PVC-PE melt blends: Effects of molecular architecture, content, and MFI of PE, Journal of Vinyl and Additive Technology, 12(3): 115-123.

Unar, I. N., Soomro, S. A. and Aziz, S., 2010. Effect of various additives on the physical properties of polyvinylchloride resin, Pakistan Journal of Analytical and Environmental Chemistry, 11(2): 44-50.

Yuniari, A. dan Kasmudjiastuti, E., 2012. Spektroscopy FTIR dan sifat mekanik nanokomposit grafting HDPE dan NPCC. Majalah Kulit, Karet dan Plastik, 28(2): 89-96. 
